\title{
Effect of thermal stratification on interflow travel time in stratified reservoir
}

\author{
Xiao-feng ZHANG ${ }^{1}$, Shi REN ${ }^{\dagger+1}$, Jun-qing LU ${ }^{2,3}$, Xin-hua LU ${ }^{1}$ \\ ( ${ }^{1}$ State Key Laboratory of Water Resources and Hydropower Engineering Science, Wuhan University, Wuhan 430072, China) \\ ( ${ }^{2}$ South China Institute of Environmental Science, Guangzhou 510655, China) \\ ( ${ }^{3}$ State Environmental Protection Key Laboratory of Water Environmental Simulation and Pollution Control, Guangzhou 510655, China) \\ †E-mail: renshi@whu.edu.cn \\ Received Sept. 6, 2014; Revision accepted Jan. 5, 2015; Crosschecked Mar. 23, 2015
}

\begin{abstract}
This study is focused on the impact of thermal stratification on interflow travel time. A quantitative relation between buoyancy frequency and interflow travel time is theoretically derived based on the Bernoulli principle of energy conservation. Experiments and numerical simulations are carried out to validate the applicability of the proposed relation. For experiments, interflow movement is successfully detected in a small-depth water tank by releasing a denser flow into a temperature stratification environment. For numerical simulations, a vertical 2D renormalization group (RNG) $k-\varepsilon$ model is developed to simulate the interflow. The results both of the experiments and of the numerical simulations verify our proposed theory. The derived analytic relation is useful for the prediction of contaminant travel time in reservoirs and in assisting pollution control.
\end{abstract}

Key words: Interflow, Travel time, Stratification, Buoyancy frequency, Renormalization group (RNG) $k-\varepsilon$ model doi: 10.1631 jzus.A1400269

Document code: A

CLC number: TV143

\section{Introduction}

Once an inflow with some contaminant (such as pesticides and toxic chemical spill) enters a reservoir, its transport process is governed by various factors, e.g., advection, dispersion, diffusion, and flow conditions ( $\mathrm{Gu}$ and Chung, 2003), and the transport process mainly controls the residence time of the contaminant in the reservoir (Rueda et al., 2006). As most reservoirs tend to become thermally stratified (a temperature gradient in the vertical direction, including hypolimnion, thermocline, and epilimnion), which can change with weather and season (Imberger, 1985), the transport process of contaminant can be complicated.

\footnotetext{
${ }^{\ddagger}$ Corresponding author

* Project supported by the National Natural Science Foundation of China (Nos. 51409195, 51379155, and 50909047)

(D) ORCID: Xiao-feng ZHANG, http://orcid.org/0000-0003-0111-5822; Shi REN, http://orcid.org/0000-0002-1399-0192

(C) Zhejiang University and Springer-Verlag Berlin Heidelberg 2015
}

Due to the density difference between the contaminated inflow and the ambient water, a density current forms in the ambient water. The density difference between inflow and ambient water may arise from both temperature differences and variations in solute concentrations (Chen et al., 2006; Chung et al., 2009; An et al., 2012; An and Julien, 2014), and the inflow can be a tributary from an upstream river, transferred water from another reservoir or contaminant spill from a location (Gu and Chung, 2003; de Cesare et al., 2006; Umeda et al., 2006). An overflow (Fig. 1) moves forward on the surface of water and is formed if the density of the inflow is lighter than that of the ambient water. A denser inflow moves along the bed slope as an underflow (Fig. 1). If the ambient water is thermally stratified, the inflow separates from the bottom slope and penetrates horizontally into the ambient water as an interflow where it becomes neutrally buoyant (Alavian et al., 1992; Fernandez and Imberger, 2008; Cortés et al., 2014a). Thus, the 
contaminant can be transported to different depths of a reservoir by different flow patterns (Wells and Nadarajah, 2009; Cortés et al., 2014b).

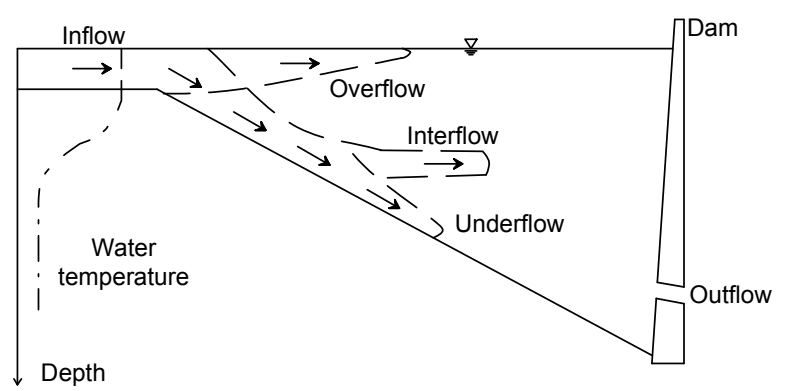

Fig. 1 Flow patterns of density current in a stratified environment

The solid arrows show the flow direction, the dashed line represents the zone of different flow patterns, and the dash-dot line represents the vertical temperature distribution

Previous studies on density currents in thermally stratified reservoirs found that thermal stratification has a significant impact on interflow travel time. Gu et al. (1996) and Gu and Chung $(1998 ; 2003)$ used various simulation models (1D integral model, 2D mixing-length model, and code CE-QUAL-W2) to investigate the density current in a thermally stratified environment. They studied the effects of inflow boundary conditions, ambient stratification, and geometry on the behavior of a density current, and found that an inverse relationship exists between ambient stratification and interflow travel time. This was later confirmed by Ahlfeld et al. (2003) using the code CE-QUAL-W2, a 2D and laterally averaged hydrodynamic and water quality model. Ahlfeld et al. (2003) analyzed the relationship with field data from the Quabbin-Wachusett reservoir system, and they found a linear inverse relationship between vertical temperature difference and travel time of interflow. However, to the best knowledge of the authors, an analytical model to verify the impact of thermal stratification on the interflow travel time in thermal stratified environment has not yet been reported. As the stratification affects the flow process of the inflow, the travel time of a contaminant in a reservoir is governed by the thermal stratification when the inflow forms an interflow.

A density current into stratified surroundings is also called as intrusive gravity current (IGC) which travels horizontally with a constant velocity $U$ in stratified surroundings for a time after releasing (Flynn and Sutherland, 2004; Shin et al., 2004; Ungarish, 2005; 2006; Nokes et al., 2008). Overflow and underflow are similar to the IGC travel along the top and bottom boundaries of stratified surroundings when its density is less or greater than the ambient water. If the ambient water is continuously stratified, IGC can travel along its level of neutral buoyancy, the height at which the density of the intrusion is the same as that of the ambient fluid. Interflow is similar to this movement. Cheong et al. (2006), Bolster et al. (2008), and Maurer et al. (2010) studied the intrusive speed of density current or IGC which travels along the neutral buoyancy depth in a continuously stratified medium. They found that IGC travelled along the top and bottom boundaries with the maximum intrusive speed, while IGC travelled along the mid-depth of ambient water with the minimum intrusive speed.

Obviously, the travel time of an interflow in stratified surroundings is related to the constant interflow velocity. Chung and $\mathrm{Gu}(1998)$ and Ahlfeld et al. (2003) found that the travel time of interflow is related to temperature difference, but they did not predict the interflow velocity in thermally stratified surroundings. In this study, to help better understand the influence of thermal stratification on interflow travel time, a model from energy conservation is developed to predict the velocity of interflow in a thermally stratified environment. The results help to analyze the relation among buoyancy frequency, the thermal stratification, and the interflow travel time. Experiments and a 2D numerical model are implemented to verify this relation. The results can help understanding of the effect of thermal stratification on the behavior of an interflow.

\section{Analytical model}

When an inflow containing some contaminant passes into a thermally stratified reservoir (no matter what its source, e.g., tributary, transferred water from another reservoir, or contaminant spill from a location on the reservoir), according to the density difference from the temperature stratification within the reservoir and the concentration of contaminant between inflow and ambient water, the inflow can take various flow regimes (overflow, interflow, and underflow). 
Fig. 2 illustrates the schematic process for the movement of interflow in such stratified surroundings.

A coordinate system is shown: $x$ denotes the horizontal distance, while $y$ is the height from the centerline of the interflow in the vertical direction. $\rho_{\mathrm{a}}$ is the density of interflow, and $D$ is its thickness. The temperature stratification is similar along the horizontal axis, $\rho(y)$ represents the density of water at depth $y$, and $H_{\mathrm{i}}$ is the depth of the interflow centerline. We suppose that the velocity of interflow is $U$ (assumed uniform in the vertical direction), and neglect the energy loss during the movement.

The flow is assumed to be hydrostatic, and thus the pressure distributions along $A F$ and $C E$ give that:

$A F$ :

$$
P=\left\{\begin{array}{lr}
\int_{D / 2}^{H_{\mathrm{i}}} \rho(y) g \mathrm{~d} y+\int_{y}^{D / 2} \rho_{\mathrm{a}} g \mathrm{~d} y, & 0 \leq y<D / 2, \\
\int_{y}^{H_{\mathrm{i}}} \rho(y) g \mathrm{~d} y, & D / 2 \leq y<H_{\mathrm{i}},
\end{array}\right.
$$

$C E$ :

$$
P=\int_{y}^{H_{\mathrm{i}}} \rho(y) g \mathrm{~d} y, \quad 0 \leq y \leq H_{\mathrm{i}},
$$

where $g$ is the acceleration due to gravity.

By further assuming that the streamline is horizontal, then according to Bernoulli's principle of energy conservation along $A B$ and $B C$, we have

$$
P_{A}=P_{B}, \quad P_{B}=P_{C}+\frac{1}{2} \rho U^{2},
$$

where $\rho$ is the density of water.

By combination of Eqs. (1)-(3), we can obtain:

$$
\begin{aligned}
& \int_{0}^{D / 2} \rho_{\mathrm{a}} g \mathrm{~d} y+\int_{D / 2}^{H_{\mathrm{i}}} \rho(y) g \mathrm{~d} y \\
& =\int_{0}^{H_{\mathrm{i}}} \rho(y) g \mathrm{~d} y+\frac{1}{2} \rho(0) U^{2} .
\end{aligned}
$$

As the interflow travels at the depth of equal buoyancy, $\rho_{\mathrm{a}}$ is equal to that of the surrounding water.

$$
\rho_{\mathrm{a}}=\rho(0) .
$$

A linear density variation is considered within the thermocline (Gu and Chung, 1998; 2003):

$$
\rho(y)=\rho(0)-\frac{\left(\rho_{\mathrm{b}}-\rho_{\mathrm{t}}\right)}{h} y,
$$

where $\rho_{\mathrm{b}}$ and $\rho_{\mathrm{t}}$ are the densities of ambient water at bottom boundary and top boundary of the thermocline, respectively; and $h$ is the thickness of the thermocline.

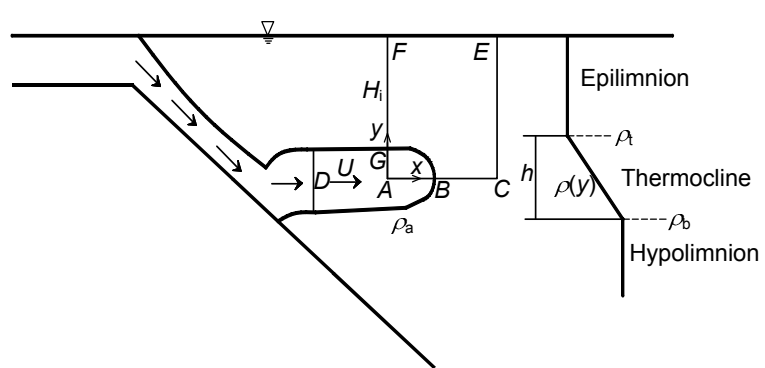

Fig. 2 Movement of an interflow in stratified surrounding

Substituting Eqs. (5) and (6) into Eq. (4) gives

$$
U=\frac{D}{2} \sqrt{\frac{\rho_{\mathrm{b}}-\rho_{\mathrm{t}}}{\rho_{\mathrm{a}}} \frac{g}{h}} .
$$

To quantify the effect of stratification, the buoyancy frequency $N$ is defined as

$$
N=\sqrt{-\frac{g}{\bar{\rho}} \frac{\mathrm{d} \rho}{\mathrm{d} z}}=\sqrt{\frac{g}{\rho_{\mathrm{a}}} \frac{\rho_{\mathrm{b}}-\rho_{\mathrm{t}}}{h}}
$$

where $\bar{\rho}$ is the average density of ambient water. Substituting Eq. (8) into Eq. (7) gives

$$
U=D N / 2 \text {. }
$$

Benjamin (1968) derived a theory from energyconservation for a density current propagating in a stationary liquid. According to that theory, the thickness of the density current $(D)$ is approximately half of the water depth $(H)$ when the density current travel along the bottom boundary of ambient water as an underflow. From the point of view of continuity and momentum flux conservation of the flow, Shin et al. (2004) verified this relation between $D$ and $H$ for the energy-conserving current in the underflow:

$$
D=H / 2 \text {. }
$$


Assuming that the bottom boundary of the thermocline coincides with the bottom boundary of the ambient stratified water, the interflow can be regarded as an underflow as it travels along that bottom boundary. Then substitution of Eq. (10) into Eq. (9) gives

$$
U=N H / 4 .
$$

Note that Eq. (11) is derived by neglecting energy loss, and this conclusion is established in underflow condition. Through experiments in a uniformly stratified fluid, Maxworthy et al. (2002) investigated the bottom boundary IGC (called underflow as well). From dimensional analysis, they proposed the dimensionless internal Froude number which took the form of

$$
F=U / N H .
$$

One could use the equation $U=F N H$ to describe the velocity of the intrusive speed of an underflow in the stratified fluid. Through experimental data and analysis, Ungarish (2006) suggested the value of $F$ is 0.25 by considering energy conservation. Our result for the prediction of underflow intrusive speed in thermally stratified surroundings is equal to 0.25 as well. This coincidence proves that a linear relation exists between the speed of density current and buoyancy frequency. It should be mentioned that the parameter 0.25 only exists in underflow, and the velocity of interflow is shown in Eq. (9).

If the length of reservoir is $L$, the travel time of contaminant $\left(t_{\mathrm{i}}\right)$ can be calculated from the velocity of interflow in Eq. (9) by assuming constant velocity during the movement:

$$
t_{\mathrm{i}}=\frac{L}{U}=\frac{2 L}{D N} .
$$

Eq. (13) indicates that there exists an inverse relation between the travel time of the interflow and thermal stratification defined as the buoyancy frequency. This relationship is consistent with previous reported numerical results and filed data. To further validate the above relationship, we carried out experiments and numerical simulations of the interflow in thermally stratified surroundings.

\section{Experimental}

\subsection{Experimental apparatus}

A schematic diagram of the experimental apparatus and coordinate system is shown in Fig. 3. The apparatus consists of an inlet tank, a main tank, and an outlet tank. The inlet and outlet tanks are of the same size: $0.184 \mathrm{~m}$ long, $0.284 \mathrm{~m}$ wide, and $0.995 \mathrm{~m}$ deep. The main tank is $1.70 \mathrm{~m}$ long, $0.184 \mathrm{~m}$ wide, and $0.995 \mathrm{~m}$ deep, with a slope angle $\theta=25.3^{\circ}$. These three parts are separated by two partitions with some holes which ensure that water can move from one part to another. With slots on both the transverse sides of the partitions, a rectangular baffle plate can be placed at different depths to control the position of the outlet. There is a submersible pump with pipes to provide the initial flow rate at the inlet. A valve on the pipe can regulate the flow rate of the inlet. Six Atman crystal electric heater rods are set at the same depth to produce temperature stratification.

\subsection{Experimental realization of temperature stratification}

Before the experiments, the tank was filled with cold water to a depth of $53.5 \mathrm{~cm}$. Six Atman crystal electric heater rods (each one with operating voltage 220-240 V and electric power $200 \mathrm{~W}$ ) were used to realize temperature stratification in the vertical direction. They are fixed on the glass wall by circular chucks at the same height below the water surface. As the indoor water temperature in our laboratory is more than $15^{\circ} \mathrm{C}$, the heating temperature of a heater rod is in range of $20-30{ }^{\circ} \mathrm{C}$ to form the thermal stratification. In each experiment, the same heating temperature of every rod was set. Water temperature $(T)$ in vertical direction is measured by some ST-2 digital thermometers (produced by Elitech, China, and the precision of temperature measurement is $0.1^{\circ} \mathrm{C}$ ). All the thermometers were calibrated by measuring a water body at the same time. The thermometer probes are fixed every $1 \mathrm{~cm}$ at $7-22 \mathrm{~cm}$ depth on the glass wall. In addition, another two thermometers were used to measure water surface temperature and water bottom temperature. These thermometers can show vertical temperature distribution of ambient water at the same time. As shown in Fig. 4, the vertical distribution of water temperature tends to be stable after heating, with a large temperature gradient in the vertical 


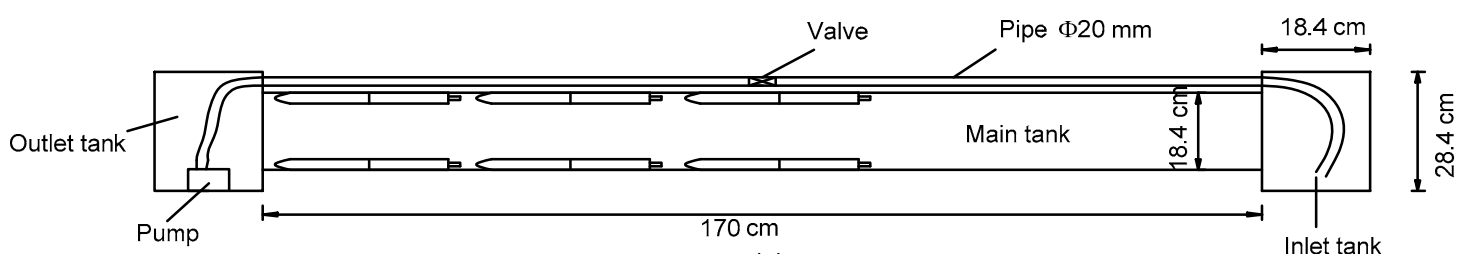

(a)

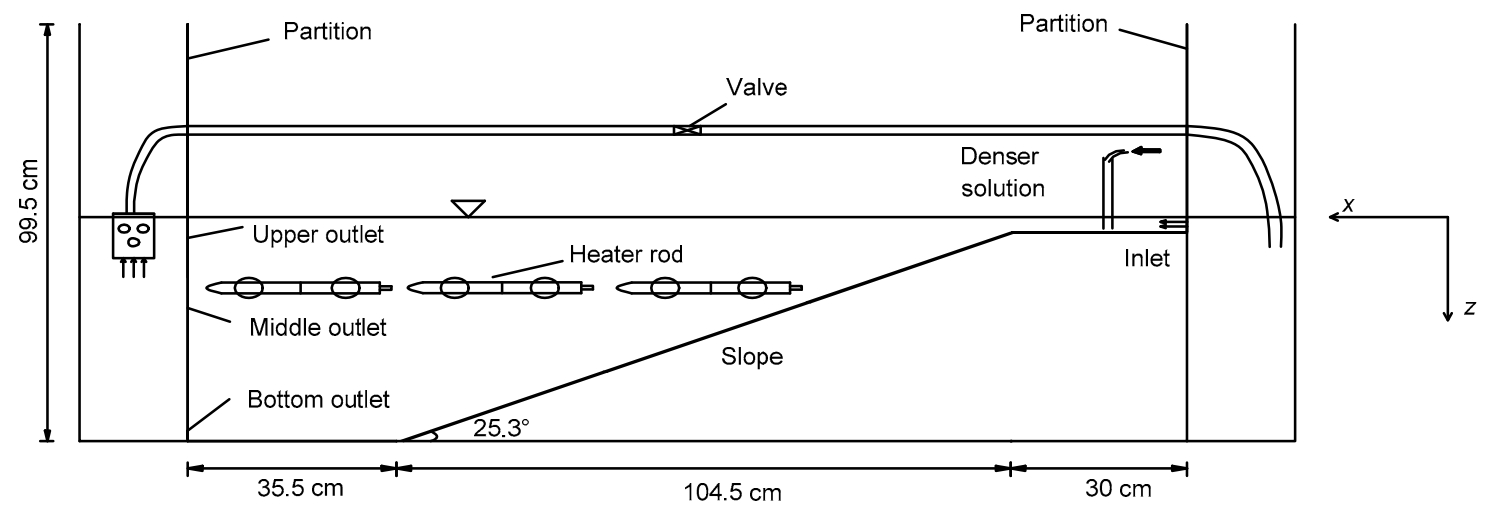

(b)

Fig. 3 Schematic views of experimental apparatus

(a) Top view; (b) Side view. Coordinate system is shown: $x$ is the horizontal distance measured from inlet, while $z$ is the depth measured from water surface in vertical direction

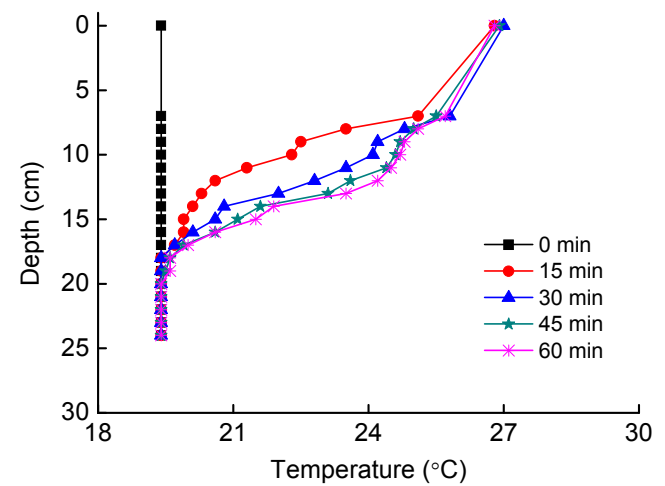

Fig. 4 Temperature distribution in the vertical direction with time

The initial temperature of cold water is around $19.4{ }^{\circ} \mathrm{C}$, and the heating temperature of each heater rod is $28^{\circ} \mathrm{C}$. A temperature difference in the vertical direction is formed by this way of heating

direction from 0 to $18 \mathrm{~cm}$ and a homogeneous temperature region under $18 \mathrm{~cm}$. This temperature gradient is similar to the thermal stratification of the thermocline in a thermally stratified reservoir.

For simplicity, a linear relation between water temperature and depth is considered in the thermocline. The buoyancy frequency $(N)$ is used to describe the initial stratified intensity of the ambient water, as shown in Eq. (8), where $\rho_{\mathrm{a}}$ is the reference density, $\left(\rho_{\mathrm{b}}+\rho_{\mathrm{t}}\right) / 2$. The density of ambient water is calculated by its temperature from Eq. (21).

\subsection{Experiment results}

The main experiment was performed by suddenly releasing denser fluid at the top of the slope in the main tank into the stratified environment. A solution of potassium permanganate was chosen as the denser fluid at the inlet; in addition to its density difference, it produces a difference in color which provides a visual and measurable tracer. The density of the inflow solution $\left(\rho_{0}\right)$ can be calculated from Eq. (14) as the temperature and concentration of the solution are given:

$$
\rho_{0}=\rho_{\mathrm{T}}+\left(1-\frac{\rho_{\mathrm{T}}}{\rho_{\mathrm{S}}}\right) c,
$$

where $\rho_{\mathrm{T}}$ is the water density which depends on the temperature of the water and is calculated from Eq. (21); $\rho_{\mathrm{S}}$ is the density of potassium permanganate $\left(2703 \mathrm{~kg} / \mathrm{m}^{3}\right)$; and $c$ is its concentration. In this study, the concentration of the inflow solution is $0.005 \mathrm{~g} / \mathrm{ml}$, which is relatively high. In our experiment, we released the denser solution for a while (almost $100 \mathrm{ml}$ ), and the density of the inflow decreased gradually due 
to mixing and entrainment. To investigate the interflow which could pass through the whole main tank, this concentration was chosen. This phenomenon is similar to the spill of a contaminant of high concentration into stratified surroundings forming a density current.

The solution moved into the temperature stratified environment by a constant inflow from an inlet which was controlled by a submersible pump and a valve. The condition at the inlet was carefully controlled to ensure that the inflow was approximately uniform across the width of the tank. This was achieved by using a T-type glass tube with width the same size as the main tank to add the inflow solution. The inflow boundary conditions in the experiments are inflow density of solution $\left(\rho_{0}\right)$, temperature of inflow solution $\left(T_{0}\right)$, inflow rate of per unit width $\left(Q_{0}\right)$, and inflow water depth $\left(h_{0}\right)$. Inflow water depth $h_{0}=4.5 \mathrm{~cm}$ for all experiments.

The typical formation of an interflow into a temperature stratified environment is shown in Fig. 5. In this experiment, the inflow temperature is $19.8^{\circ} \mathrm{C}$ and the concentration of the solution is $0.005 \mathrm{~g} / \mathrm{ml}$, and thus $\rho_{0}=1001.31 \mathrm{~kg} / \mathrm{m}^{3}$ which is denser than the density of ambient water at any temperature. However, the density decreased gradually due to mixing and entrainment during the movement on the slope. Once the density current found its neutral depth in the ambient, it separated from the slope and penetrated horizontally into the ambient water as an interflow.

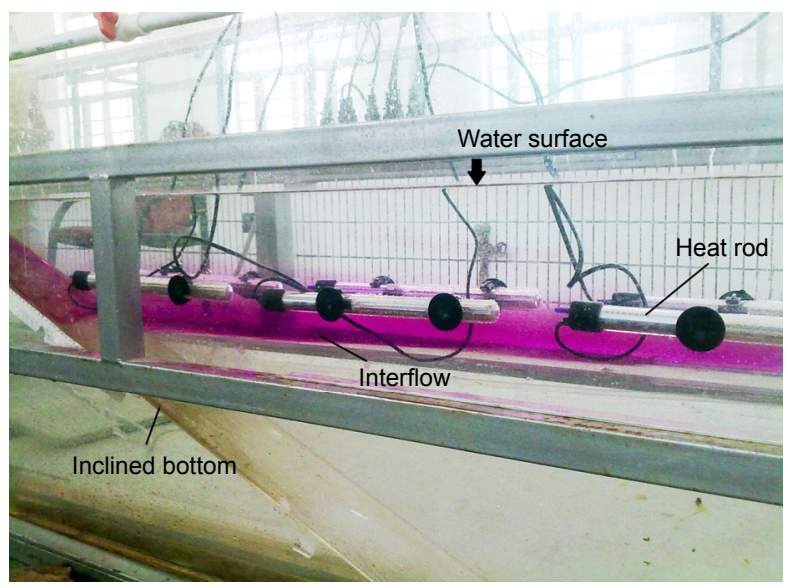

Fig. 5 Formation of an interflow
The movement of the interflow was performed under different temperature stratification conditions to verify the relation between buoyancy frequency and travel time of interflow. The details of these conditions are given in Table 1, which contains values of the controlling parameters and some measurement observations. $t_{\mathrm{i}}$ is the travel time of the interflow, defined as the time after release when the head of interflow arrives at the outlet. Due to the difficulty of monitoring the concentration of the interflow, we took interflow travel time as the time the tracer arrived at the outlet.

Table 1 Physical experimental conditions for interflow movement in a stratified environment

\begin{tabular}{lccccc}
\hline Case & $\begin{array}{c}Q_{0} \\
\left(\mathrm{~cm}^{2} / \mathrm{s}\right)\end{array}$ & $\begin{array}{c}\rho_{0} \\
\left(\mathrm{~kg} / \mathrm{m}^{3}\right)\end{array}$ & $\begin{array}{c}\text { Outlet } \\
\text { position }\end{array}$ & $N\left(\mathrm{~s}^{-1}\right)$ & $t_{\mathrm{i}}(\mathrm{s})$ \\
\hline $\mathrm{A}$ & 1.80 & 1002.21 & Middle & 0.24 & 511 \\
$\mathrm{~B}$ & 1.80 & 1002.23 & Middle & 0.29 & 491 \\
$\mathrm{C}$ & 1.80 & 1002.21 & Middle & 0.30 & 462 \\
$\mathrm{D}$ & 1.80 & 1002.20 & Middle & 0.35 & 445 \\
$\mathrm{E}$ & 1.80 & 1002.20 & Middle & 0.37 & 410 \\
\hline
\end{tabular}

The vertical temperature distributions in the experiments $\mathrm{A}-\mathrm{E}$ are shown in Fig. 6. In these experiments, the water temperature in the hypolimnion was almost the same, while the temperature gradient changed in the thermocline. A reference time $t_{\mathrm{r} 1}$ $\left(t_{\mathrm{r} 1}=\mathrm{l} / U_{0}=h_{0} l / Q_{0}\right.$, where $l$ is the length of the main tank) is used to normalize the interflow travel time and the buoyancy frequency. The result (Fig. 7) suggests that the interflow travels faster in ambient water with larger buoyancy frequency.

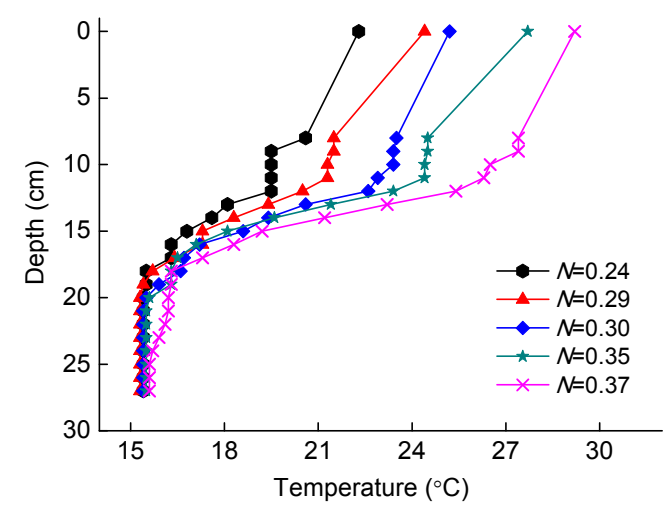

Fig. 6 Temperature distribution in experiments A-E 


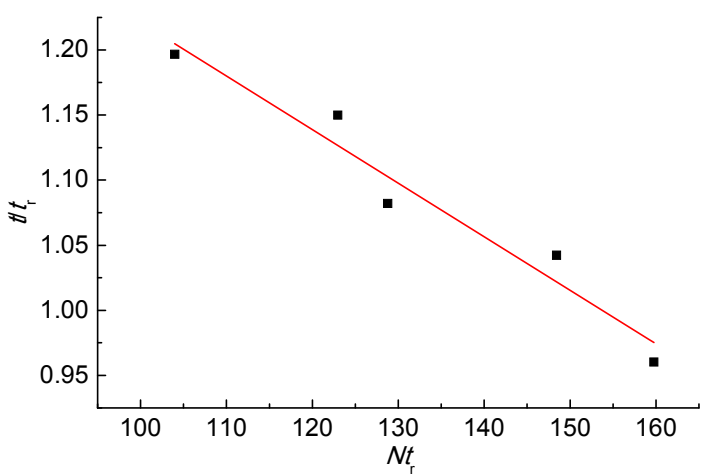

Fig. 7 Effect of buoyancy frequency on the travel time of the interflow in experiments

\section{Numerical evidence}

\subsection{Mathematical formulations}

A vertical 2D simulation model was used in this numerical experimental study to further verify that the travel time of the interflow in a thermal stratified reservoir is influenced by stratification. The Reynolds averaged equations with the renormalization group (RNG) $k-\varepsilon$ model were used for the model of turbulent flow. The governing equations in a $2 \mathrm{D}$ system are the continuity equation, horizontal and vertical momentum equations, mass transport equation, turbulence kinetic energy and dissipation rate equations, and equation of state.

$$
\begin{gathered}
\frac{\partial \rho}{\partial t}+\frac{\partial\left(\rho u_{i}\right)}{\partial x_{i}}=0 \\
\frac{\partial \rho u_{i}}{\partial t}+\frac{\partial\left(\rho u_{i} u_{j}\right)}{\partial x_{j}}=-\frac{\partial p}{\partial x_{i}}+\rho f_{i} \\
+\frac{\partial}{\partial x_{j}}\left(\mu \frac{\partial u_{i}}{\partial x_{j}}-\rho \overline{u_{i}^{\prime} u_{j}^{\prime}}\right)+\beta \rho g_{i} \Delta T \\
\frac{\partial \rho T}{\partial t}+\frac{\partial\left(\rho u_{i} T\right)}{\partial x_{j}}=\frac{\partial}{\partial x_{j}}\left(\frac{\mu}{\sigma_{\mathrm{T}}} \frac{\partial T}{\partial x_{j}}-\rho \overline{u_{j}^{\prime} T}\right) \\
\frac{\partial \rho c}{\partial t}+\frac{\partial\left(\rho u_{i} c\right)}{\partial x_{j}}=\frac{\partial}{\partial x_{j}}\left(\frac{\mu}{\sigma_{\mathrm{c}}} \frac{\partial c}{\partial x_{j}}-\rho \overline{u_{j}^{\prime} c}\right) \\
\frac{\partial \rho k}{\partial t}+u_{i} \frac{\partial \rho k}{\partial x_{i}} \\
=\frac{\partial}{\partial x_{\mathrm{i}}}\left[\left(\mu+\frac{\mu_{\mathrm{t}}}{\sigma_{k}}\right) \frac{\partial k}{\partial x_{i}}\right]+G_{\mathrm{k}}+G_{\mathrm{b}}-\rho \varepsilon
\end{gathered}
$$

$$
\begin{aligned}
\rho= & \left(0.102027692 \times 10^{-2}+0.667737262 \times 10^{-7} T\right. \\
& -0.905345843 \times 10^{-8} T^{2}+0.864372185 \times 10^{-10} T^{3} \\
& -0.642266188 \times 10^{-12} T^{4}+0.105164434 \times 10^{-17} T^{7} \\
& \left.-0.104868827 \times 10^{-19} T^{8}\right) \times 9.8 \times 10^{5} .
\end{aligned}
$$

In the above equations, $x_{i}(i=1,2)$ and $x_{j}(j=1,2)$ denote a coordinate system $x$ and $z ; u_{i}(i=1,2)$ is the mean velocity component in the Cartesian coordinate $\operatorname{system}(x, z) ;-\overline{u_{i}^{\prime} u_{j}^{\prime}}$ are Reynolds stresses; $f_{i}\left(\mathrm{~m} / \mathrm{s}^{2}\right)$ is the force in the $x_{i}$ direction; $t(\mathrm{~s})$ is the time; $B(\mathrm{~m})$ is the reservoir width; $g_{i}=(0, g)$ is the acceleration due to gravity $\left(\mathrm{m} / \mathrm{s}^{2}\right) ; p\left(\mathrm{~N} / \mathrm{m}^{2}\right)$ is the dynamic pressure; $\mu$ $(\mathrm{kg} /(\mathrm{m} \cdot \mathrm{s}))$ is the dynamic viscosity; $k\left(\mathrm{~m}^{2} / \mathrm{s}^{2}\right)$ is the kinetic energy of turbulence; $\varepsilon\left(\mathrm{m}^{2} / \mathrm{s}^{3}\right)$ is the turbulence dissipation rate; $\mu_{\mathrm{t}}(\mathrm{kg} /(\mathrm{m} \cdot \mathrm{s}))$ is the turbulence viscosity; $T\left({ }^{\circ} \mathrm{C}\right)$ is temperature; $c$ is the concentration of density flow; $-\overline{u_{j}^{\prime} T}$ and $-\overline{u_{j}^{\prime} c}$ are the turbulent fluxes of temperature and concentration; $\sigma_{\mathrm{T}}, \sigma_{\mathrm{c}}, \sigma_{k}$, and $\sigma_{\varepsilon}$ are the turbulent Prandtl numbers for temperature, mass transport, $k$, and $\varepsilon$, respectively. $G_{\mathrm{k}}$ $\left(\mathrm{kg} /\left(\mathrm{m} \cdot \mathrm{s}^{3}\right)\right)$ is the generation of turbulence kinetic energy due to the mean velocity gradient; $G_{\mathrm{b}}\left(\mathrm{kg} /\left(\mathrm{m} \cdot \mathrm{s}^{3}\right)\right)$ is the generation of turbulence kinetic energy due to buoyancy; and $C_{1 \delta}, C_{2 \delta}$, and $C_{3 \varepsilon}$ are parameters of $k-\varepsilon$ model.

$$
\mu_{\mathrm{t}}=\rho C_{\mu} \frac{k^{2}}{\varepsilon}
$$

where $C_{\mu}$ is the eddy velocity which is a constant (0.0845) in RNG $k-\varepsilon$ model (Yin et al., 1996).

$$
G_{\mathrm{k}}=-\rho \overline{u_{i}^{\prime} u_{j}^{\prime}} \frac{\partial u_{i}}{\partial x_{j}}, \quad G_{\mathrm{b}}=-\beta \rho g_{i} \overline{u_{i}^{\prime} T}
$$

Furthermore, $\sigma_{\mathrm{T}}=0.85, \sigma_{\mathrm{c}}=1.0, \sigma_{k}=0.7179, \sigma_{\varepsilon}=0.7179$, $C_{1 \varepsilon}=1.43, C_{2 \varepsilon}=0.43$, and 


$$
C_{3 \varepsilon}=\tanh \left|\frac{u_{2}}{u_{1}}\right| .
$$

Eqs. (15)-(20) are discretized using the finitevolume method on a staggered grid. The semi-implicit method for pressure-linked equations consistent (SIMPLEC) algorithm is used to couple the velocity and pressure, which is an improved method of the semi-implicit method for pressure-linked equations (SIMPLE) for calculating incompressible flow (van Doormaal and Raithby, 1984).

\subsection{Numerical results}

A uniform grid system is used in the simulations. The grid system consists of 50 segments with a length of $0.4 \mathrm{~m}$ along the longitudinal axis, and 50 layers with thickness $0.08 \mathrm{~m}$. A rectangular cross section of the water body is assumed. The thermocline was set at layers 31 to 40 , located at depths from $0.8 \mathrm{~m}$ to $1.6 \mathrm{~m}$; for simplicity, a linear density variation within the thermocline is assumed. The bottom bed is assumed to be smooth and has a uniform slope of 1:5.31. The water depth rises gradually from the inlet boundary $(0.24 \mathrm{~m})$ to the outlet boundary $(4.0 \mathrm{~m})$.

As described above, the interflow in the experiments was performed by suddenly releasing a denser solution into thermally stratified surroundings. This simulated the movement of contaminant spill from a location on the reservoir. In the numerical simulations, we simulated tributary inflow from river to reservoir. The density difference between the inflow of a tributary and the ambient water mainly comes from a temperature difference. As in the study of $\mathrm{Gu}$ and Chung (1998), constant inflow discharge and contaminant concentration are used at the inlet in all simulations. Although the interflow formed from various patterns of inflow, the impact of buoyancy frequency on the travel time of interflow is not influenced by difference of inflow conditions. Constant inflow discharge and contaminant concentration loading at the upstream boundary are specified at $0.005 \mathrm{~m}^{2} / \mathrm{s}$ and $10 \mathrm{mg} / \mathrm{L}$, respectively. Outflow discharge at the downstream boundary is assumed to be equal to the inflow discharge. Uniform velocity (the ratio of inflow discharge to the area of each cross section) and zero concentration were used as the initial reservoir conditions.
The density of the inflow is a function of the temperature and concentration as shown in Eq. (14). However, in the numerical simulations, the inflow concentration $\left(C_{0}\right)$ is $10 \mathrm{mg} / \mathrm{L}$ for all simulations. According to Eq. (14), this inflow concentration does not affect the density. Therefore, the inflow density can be simplified to a function of temperature only, as shown in Eq. (23).

Interflow travel time is defined as the time between the initiation of the interflow and its arrival in front of the dam. Ahlfeld et al. (2003) used a specified fraction of interflow water to all the outlet water to define the travel time. In this study, following the method of Ahlfeld et al. (2003), the travel time is defined as the time taken until the concentration of the interflow at the downstream boundary equals $10 \%$ of the inflow concentration $\left(C_{0}\right)$. The metric for the degree of stratification was defined as the buoyancy frequency.

As shown in Fig. 8, if the temperature of the inflow $\left(17^{\circ} \mathrm{C}\right)$ was within the range of stratified ambient water $\left(16-18^{\circ} \mathrm{C}\right)$, the inflow separates from the bottom at a depth where it achieves its equilibrium temperature, and penetrates horizontally into the reservoir as an interflow. However, as shown in Fig. 9, the inflow with a lower temperature $\left(14{ }^{\circ} \mathrm{C}\right)$ forms an interflow as well. As high temperature ambient water mixes into the inflow or is entrained from upper layers, the density of the inflow decreases leading to a decrease in the density difference between the inflow and the ambient water. The interflow travels at the depth of equal buoyancy. This process is similar to the formation of interflow in the experiments. If the inflow temperature is sufficiently low $\left(10^{\circ} \mathrm{C}\right)$ and the mixing or entrainment cannot offset the density difference, an underflow forms, not an interflow (Fig. 10). These results confirm that the 2D model can simulate the interflow arising from the temperature difference between the inflow and the thermally stratified environment. Since the intensity of stratification affects the travel time of the interflow in stratified surroundings, the inflow, travelling as the interflow under various stratification conditions, was simulated here to verify the relation between buoyancy frequency and travel time. Table 2 presents the parameters for numerical simulations of interflow under various stratification conditions, where $Q_{0}$ and 

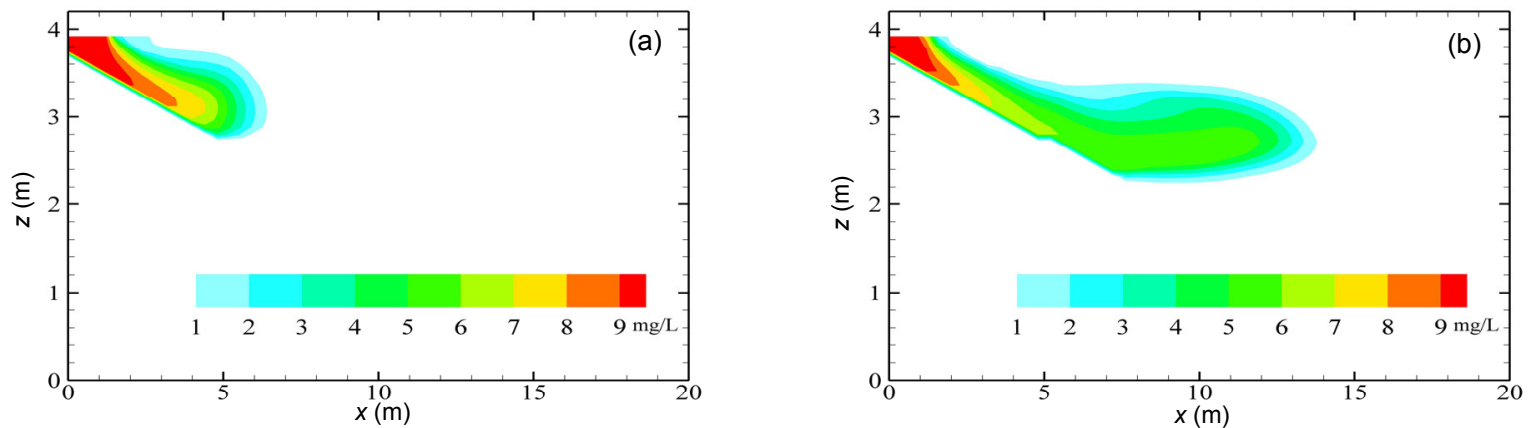

Fig. 8 Movement of interflow with inflow temperature $\left(17^{\circ} \mathrm{C}\right)$ at different times shown by the concentration contour: (a) $t_{0}=500 \mathrm{~s} ;$ (b) $t_{0}=1000 \mathrm{~s} ; t_{0}$ is time after calculating; the dam is located at the outlet boundary, $x=20 \mathrm{~m}$
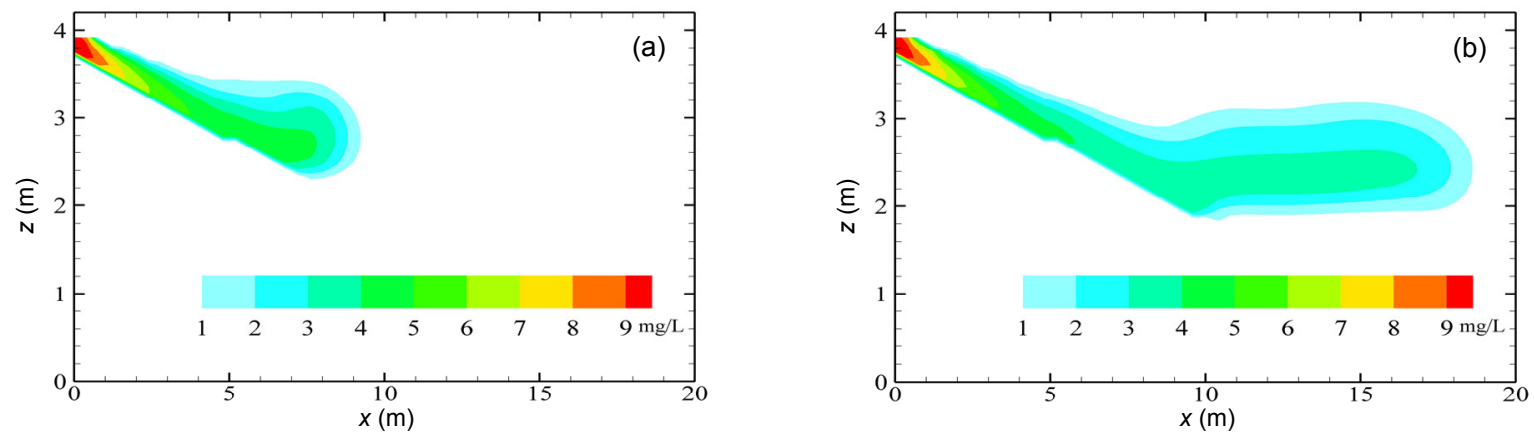

Fig. 9 Movement of interflow with lower inflow temperature $\left(14^{\circ} \mathrm{C}\right)$ at different times shown by the concentration contour: (a) $t_{0}=500 \mathrm{~s}$; (b) $t_{0}=1000 \mathrm{~s} ; t_{0}$ is the time after calculating; the dam is located at the outlet boundary, $x=20 \mathrm{~m}$
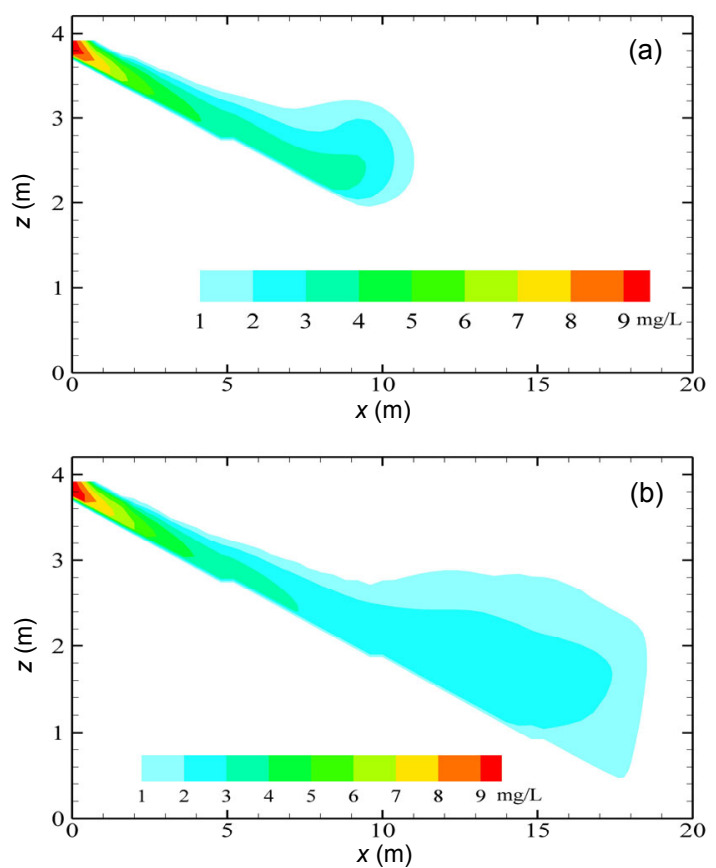

Fig. 10 Movement of underflow with sufficiently low temperature $\left(10{ }^{\circ} \mathrm{C}\right)$ at different times shown by the concentration contour: (a) $t_{0}=500 \mathrm{~s}$; (b) $t_{0}=1000 \mathrm{~s} ; t_{0}$ is the time after calculating; the dam is located at the outlet boundary, $x=20 \mathrm{~m}$
Table 2 Parameters for numerical simulations of interflow under various stratification conditions

\begin{tabular}{cccccccc}
\hline \multirow{2}{*}{ Case } & \multicolumn{2}{c}{$\begin{array}{c}\text { Inflow } \\
\text { condition }\end{array}$} & \multicolumn{2}{c}{$\begin{array}{c}\text { Stratified } \\
\text { condition }\end{array}$} & $N\left(\mathrm{~s}^{-1}\right)$ & $t_{\mathrm{i}}(\mathrm{s})$ \\
\cline { 2 - 3 } & $Q_{0}\left(\mathrm{~m}^{2} / \mathrm{s}\right)$ & $T_{0}\left({ }^{\circ} \mathrm{C}\right)$ & $T_{\mathrm{t}}\left({ }^{\circ} \mathrm{C}\right)$ & $T_{\mathrm{b}}\left({ }^{\circ} \mathrm{C}\right)$ & & \\
\hline 1 & 0.005 & 18 & 19 & 21 & 0.071 & 980 \\
2 & 0.005 & 18 & 18 & 22 & 0.101 & 860 \\
3 & 0.005 & 18 & 17 & 23 & 0.123 & 810 \\
4 & 0.005 & 18 & 16 & 24 & 0.142 & 740 \\
5 & 0.005 & 18 & 15 & 25 & 0.159 & 690 \\
6 & 0.005 & 18 & 14 & 26 & 0.174 & 670 \\
7 & 0.005 & 18 & 13 & 27 & 0.188 & 630 \\
8 & 0.005 & 18 & 12 & 28 & 0.200 & 590 \\
9 & 0.005 & 18 & 11 & 29 & 0.212 & 540 \\
10 & 0.005 & 18 & 10 & 30 & 0.223 & 530 \\
\hline
\end{tabular}

$T_{0}$ denote the inflow discharge and temperature, $T_{\mathrm{b}}$ represents the temperature of ambient water at the lower boundary of the thermocline, and $T_{\mathrm{t}}$ is the temperature of ambient water at the top boundary of the thermocline. The simulation results are shown in Fig. 11. 

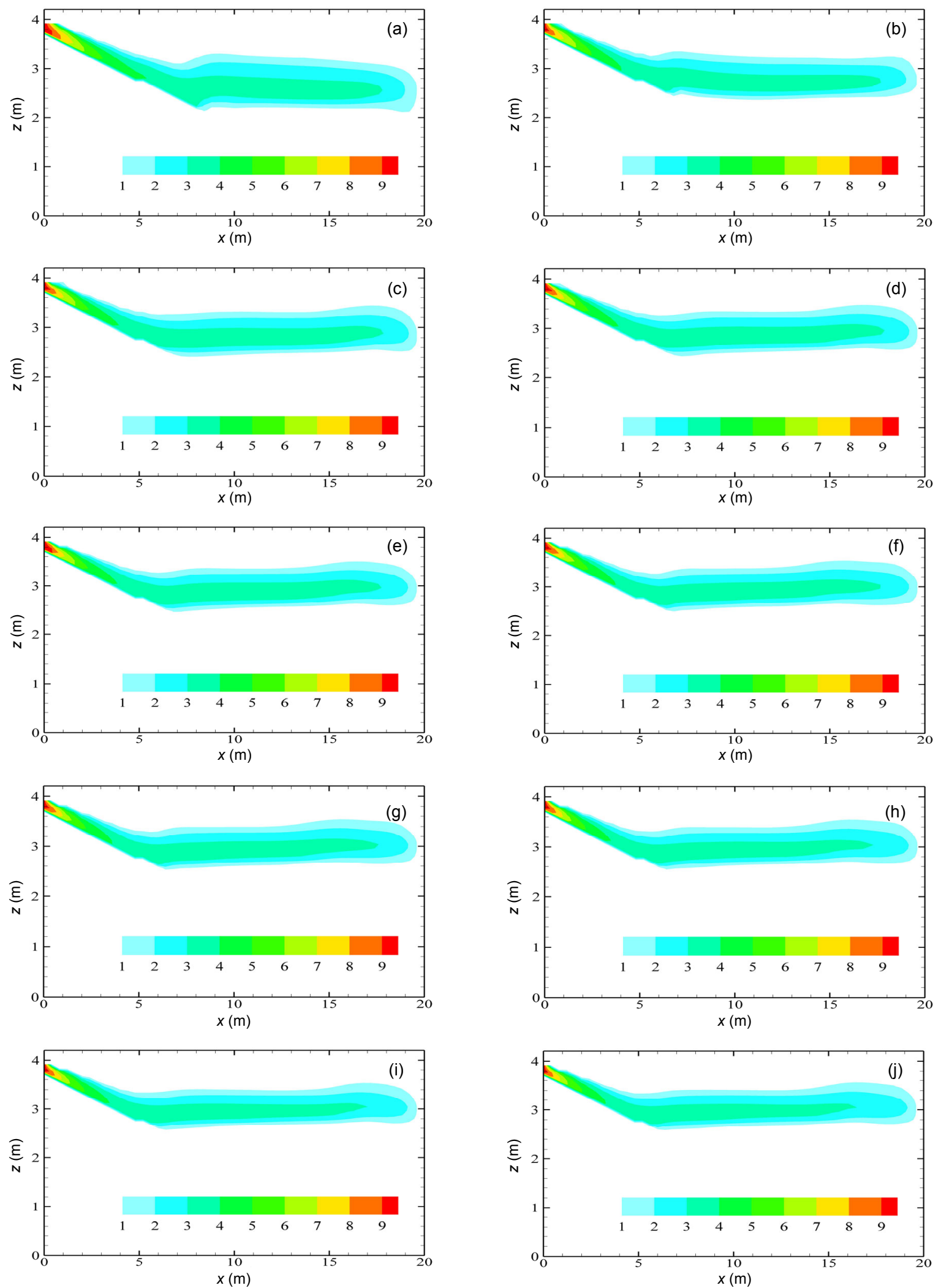

Fig. 11 Travel time of the interflow under various stratifications

(a) $N=0.071 \mathrm{~s}^{-1}, t_{\mathrm{i}}=980 \mathrm{~s}$; (b) $N=0.101 \mathrm{~s}^{-1}, t_{\mathrm{i}}=860 \mathrm{~s}$; (c) $N=0.123 \mathrm{~s}^{-1}, t_{\mathrm{i}}=810 \mathrm{~s}$; (d) $N=0.142 \mathrm{~s}^{-1}, t_{\mathrm{i}}=740 \mathrm{~s}$; (e) $N=0.159 \mathrm{~s}^{-1}, t_{\mathrm{i}}=690 \mathrm{~s}$; (f) $N=0.174 \mathrm{~s}^{-1}, t_{\mathrm{i}}=670 \mathrm{~s}$; (g) $N=0.188 \mathrm{~s}^{-1}, t_{\mathrm{i}}=630 \mathrm{~s}$; (h) $N=0.200 \mathrm{~s}^{-1}, t_{\mathrm{i}}=590 \mathrm{~s}$; (i) $N=0.212 \mathrm{~s}^{-1}, t_{\mathrm{i}}=540 \mathrm{~s}$; (j) $N=0.223 \mathrm{~s}^{-1}, t_{\mathrm{i}}=530 \mathrm{~s}$ 
Gu and Chung (1998) used the reservoir stratification number $\left(S_{\mathrm{t}}\right)$ to represent the ambient thermocline stratification. $S_{\mathrm{t}}$ was defined as the ratio of the vertical density difference in the thermocline to the difference between the inflow density of the interflow and the average density in the thermocline. Ahlfeld et al. (2003) used the vertical temperature difference $\left(\triangle T=T_{\mathrm{t}}-T_{\mathrm{b}}\right)$ to define the thermocline stratification, which can be considered as a simplified form of the metric of $\mathrm{Gu}$ and Chung (1998). Ahlfeld et al. (2003)'s study provides a better fit of temperature difference to describe the relation between stratification and the other parameters. A near-linear relation between stratification and travel time was obtained through mathematic analysis. Therefore, $N$ is used for the representation of thermocline stratification in this study to verify the relation. This metric can be considered as a transform of the previous metrics.

As shown in Fig. 11, the interflow formed in all the simulations. Since the inflow conditions are the same for all simulations, the main factor that affects the travel time of a contaminant as an interflow is the stratification of the thermocline. A reference time $t_{\mathrm{r} 2}$, defined as $t_{\mathrm{r} 2}=L / U_{0}=h_{0} L / Q_{0}$, is used for the normalization of the travel time and buoyancy frequency. The result (Fig. 12) suggests that a greater buoyancy frequency in the thermocline leads to reduction in the travel time of the interflow. The energy of the denser current comes from the density difference between itself and the surroundings. If the inflow density is the same, the higher thermal stratification leads to a bigger density difference between the inflow and

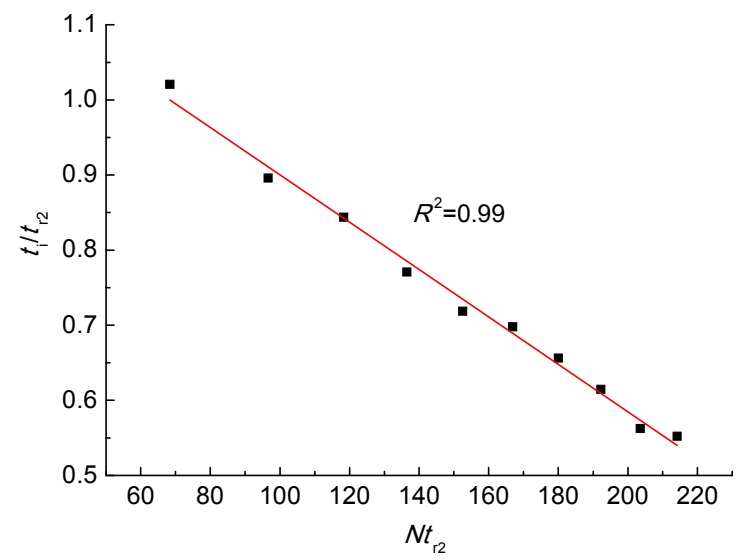

Fig. 12 Effect of buoyancy frequency on the travel time of the interflow in simulations ambient water. Therefore, the interflow accelerates in stratified surroundings as the buoyancy frequency increases. As a result, the travel time of the interflow decreases.

\section{Discussion}

Once the temperature difference flow with contaminant or suspended particles comes into a thermally stratified reservoir, where the incoming flow could be tributary from upstream river (de Cesare et al., 2006), transferred water from another reservoir, or contaminant spill from a location in the reservoir $(\mathrm{Gu}$ and Chung, 2003), the inflow may form an overflow, an interflow, or an underflow. The existing thermal stratification influences the pathway or fate of a contaminant in the reservoir, including the patterns of the formed density current, intrusion occurrence and its depth, the region or scope of contaminant in ambient water if intrusion occurs, and the travel time of contaminant flow or residence time of contaminant in reservoirs (Ahlfeld et al., 2003; Rueda et al., 2006; Rueda and MacIntyre, 2010; Cortés et al., 2014b). In this study, we mainly consider the influence of thermal stratification on the travel time of contaminant in a reservoir when interflow occurs.

In experiments, the interflow is formed by suddenly releasing a dense fluid intended to simulate contaminant spill into a reservoir, while in the numerical simulations the interflow was simulated by temperature difference inflows from an upstream river. Although the interflow was formed from different inflow patterns, the impact of buoyancy frequency on the travel time of the interflow occurs in both patterns. By assuming that the interflow moves with constant velocity, which was derived based on energy conservation, the theoretical travel time of interflow was as given in Eq. (13). Fig. 13 displays the theoretical and measured travel time of interflow against the buoyancy frequency.

As shown in Fig. 13, both the theoretical and measured travel time of interflow decreased with the increase of buoyancy frequency. The theoretical travel time of interflow is larger than that measured in all conditions. This discrepancy can be mainly ascribed to the fact that the flow cannot move with 
constant velocity all the time. The inflow moves on the bottom for a while before it gets to its neutral buoyancy level. Guo et al. (2014) investigated by numerical simulation the density current descending a slope into the linearly stratified environment and compared numerical results with the experiment data from Baines (2001). They found that the density flow accelerated firstly on the bottom slope, then decelerated (Guo et al., 2014). Therefore, the theoretical travel time of interflow with a constant velocity assumption is larger than the measured time. To accurately calculate the travel time of interflow, the details of the acceleration and deceleration processes need to be further investigated.

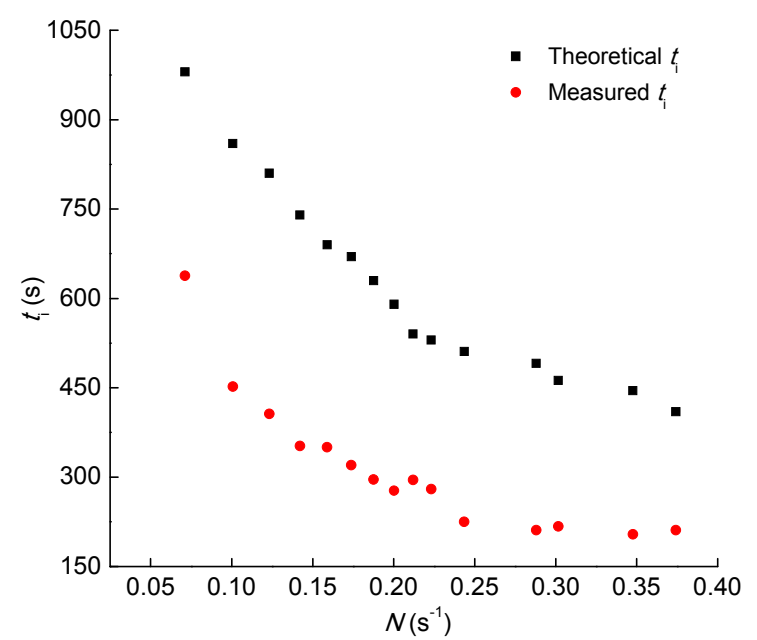

Fig. 13 Theoretical and measured travel times of the interflow in experiments and numerical simulations

Rueda et al. (2006) investigated the residence time of river water in a thermally stratified reservoir from 71 tracer river experiments over a year. The residence time is defined as the time the water remains in the reservoirs, which is also called travel time or transit time. They investigated various flow patterns in 71 tracer experiments and found that the residence time is influenced by the transport process. In the early $50 \mathrm{~d}$ of their experiments, the residence time (300 d) is much larger than that $(74 \mathrm{~d})$ in the later experiments as the reservoir was almost in a nonstratified or weakly stratified condition during the first $50 \mathrm{~d}$ (Rueda et al., 2006). Our prediction that the travel time decreases as stratification intensity increases can explain their results.

\section{Conclusions}

The effect of thermal stratification on the travel time of contaminant as an interflow was investigated in this study. The velocity of interflow in a thermally stratified environment was predicted through analytical analysis from the view of energy conservation. As a result, a linear relation between interflow travel time and buoyancy frequency was found.

The interflow was investigated experimentally by suddenly releasing dense fluid at the top of the slope. These experiments simulated the formation of interflow by a high concentration contaminant spill inflow from a location into stratified surroundings. As the density of the denser inflow was decreased by dilution and mixing with ambient water, an interflow formed when the inflow travelled at its equal buoyancy level. Through experiments with inflows moved into ambient water with different stratification intensities, a nearly linear relation between buoyancy frequency and travel time of interflow was found. This confirmed the prediction from the analytical analysis.

A 2D RNG $k$ - $\varepsilon$ model was used to simulate the interflow in a thermally stratified reservoir. In the numerical simulation, constant inflow discharge and contaminant concentration were used at the inlet, which simulated the tributary inflow from an upstream river to the reservoir. The numerical results also verified a near-linear relationship between travel time and buoyancy frequency. This result helps to better understand why interflow travel time was found to decrease with increase in the vertical temperature difference.

\section{References}

Ahlfeld, D., Joaquin, A., Tobiason, J., et al., 2003. Case study: impact of reservoir stratification on interflow travel time. Journal of Hydraulic Engineering, 129(12):966-975. [doi:10.1061/(ASCE)0733-9429(2003)129:12(966)]

Alavian, V., Jirka, G.H., Denton, R.A., et al., 1992. Density currents entering lakes and reservoirs. Journal of $\mathrm{Hy}$ draulic Engineering, 118(11):1464-1489. [doi:10.1061/ (ASCE)0733-9429(1992)118:11(1464)]

An, S., Julien, P.Y., 2014. Three-dimensional modeling of turbid density currents in Imha Reservoir, South Korea. Journal of Hydraulic Engineering, 140(5):05014004. [doi:10.1061/(ASCE)HY.1943-7900.0000851]

An, S., Julien, P.Y., Venayagamoorthy, S.K., 2012. Numerical simulation of particle-driven gravity currents. 
Environmental Fluid Mechanics, 12(6):495-513. [doi:10. 1007/s10652-012-9251-6]

Baines, P.G., 2001. Mixing in flows down gentle slopes into stratified environment. Journal of Fluid Mechanics, 443: 237-270. [doi:10.1017/S0022112001005250]

Benjamin, T.B., 1968. Gravity currents and related phenomena. Journal of Fluid Mechanics, 31(02):209-248. [doi:10. 1017/S0022112068000133]

Bolster, D., Hang, A., Linden, P.F., 2008. The front speed of intrusions into a continuously stratified medium. Journal of Fluid Mechanics, 594:369-377. [doi:10.1017/ S0022112007008993]

Chen, Y.J.C., Wu, S.C., Lee, B.S., et al., 2006. Behavior of storm-induced suspension interflow in subtropical Feitsui Reservoir, Taiwan. Limnology and Oceanography, 51(2): 1125-1133. [doi:10.4319/1o.2006.51.2.1125]

Cheong, H.B., Kuenen, J.J.P., Linden, P.F., 2006. The front speed of intrusive gravity currents. Journal of Fluid Mechanics, 552:1-11. [doi:10.1017/S002211200500772X]

Chung, S.W., Gu, R., 1998. Two-dimensional simulations of contaminant currents in stratified reservoir. Journal of Hydraulic Engineering, 124(7):704-711. [doi:10.1061/ (ASCE)0733-9429(1998)124:7(704)]

Chung, S.W., Hipsey, M.R., Imberger, J., 2009. Modelling the propagation of turbid density inflows into a stratified lake: Daecheong Reservoir, Korea. Environmental Modelling \& Software, 24(12):1467-1482. [doi:10.1016/j.envsoft. 2009.05.016]

Cortés, A., Rueda, F.J., Wells, M.G., 2014a. Experimental observations of the splitting of a gravity current at a density step in a stratified water body. Journal of Geophysical Research: Oceans, 119(2):1038-1053. [doi:10.1002/ 2013JC009304]

Cortés, A., Fleenor, W.E., Wells, M.G., et al., 2014b. Pathways of river water to the surface layers of stratified reservoirs. Limnology and Oceanography, 59(1):233-250. [doi:10. 4319/10.2014.59.1.0233]

de Cesare, G., Boillat, J.L., Schleiss, A.J., 2006. Circulation in stratified lakes due to flood-induced turbidity currents. Journal of Environmental Engineering, 132(11): 1508-1517. [doi:10.1061/(ASCE)0733-9372(2006)132: 11(1508)]

Fernandez, R.L., Imberger, J., 2008. Time-varying underflow into a continuous stratification with bottom slope. Journal of Hydraulic Engineering, 134(9):1191-1198. [doi:10. 1061/(ASCE)0733-9429(2008)134:9(1191)]

Flynn, M.R., Sutherland, B.R., 2004. Intrusive gravity currents and internal gravity wave generation in stratified fluid. Journal of Fluid Mechanics, 514:355-383. [doi:10.1017/ S0022112004000400]

Gu, R., Chung, S.W., 1998. Reservoir flow sensitivity to inflow and ambient parameters. Journal of Water Resources Planning and Management, 124(3):119-128. [doi:10. 1061/(ASCE)0733-9496(1998)124:3(119)]

Gu, R., Chung, S.W., 2003. A two-dimensional model for simulating the transport and fate of toxic chemicals in a stratified reservoir. Journal of Environmental Quality, 32(2):620-632. [doi:10.2134/jeq2003.6200]

Gu, R., McCutcheon, S.C., Wang, P.F., 1996. Modeling reservoir density underflow and interflow from a chemical spill. Water Resources Research, 32(3):695-705. [doi:10. 1029/95WR03486]

Guo, Y., Zhang, Z., Shi, B., 2014. Numerical simulation of gravity current descending a slope into a linearly stratified environment. Journal of Hydraulic Engineering, 140(12): 04014061. [doi:10.1061/(ASCE)HY.1943-7900.0000936]

Imberger, J., 1985. The diurnal mixed layer. Limnology and Oceanography, 30(4):737-770. [doi:10.4319/1o.1985.30. 4.0737]

Maurer, B.D., Bolster, D.T., Linden, P.F., 2010. Intrusive gravity currents between two stably stratified fluids. Journal of Fluid Mechanics, 647:53-69. [doi:10.1017/ S0022112009993752]

Maxworthy, T., Leilich, J.S.J.E., Simpson, J.E., et al., 2002. The propagation of a gravity current into a linearly stratified fluid. Journal of Fluid Mechanics, 453:371-394. [doi:10.1017/S0022112001007054]

Nokes, R.I., Davidson, M.J., Stepien, C.A., et al., 2008. The front condition for intrusive gravity currents. Journal of Hydraulic Research, 46(6):788-801. [doi:10.1080/ 00221686.2008.9521923]

Rueda, F.J., MacIntyre, S., 2010. Modelling the fate and transport of negatively buoyant storm-river water in small multi-basin lakes. Environmental Modelling \& Software, 25(1):146-157. [doi:10.1016/j.envsoft.2009.07. 002]

Rueda, F.J., Moreno-Ostos, E., Armengol, J., 2006. The residence time of river water in reservoirs. Ecological Modelling, 191(2):260-274. [doi:10.1016/j.ecolmodel.2005. 04.030]

Shin, J.O., Dalziel, S.B., Linden, P.F., 2004. Gravity currents produced by lock exchange. Journal of Fluid Mechanics, 521:1-34. [doi:10.1017/S002211200400165X]

Umeda, M., Yokoyama, K., Ishikawa, T., 2006. Observation and simulation of floodwater intrusion and sedimentation in the Shichikashuku Reservoir. Journal of Hydraulic Engineering, 132(9):881-891. [doi:10.1061/(ASCE) 0733-9429(2006)132:9(881)]

Ungarish, M., 2005. Intrusive gravity currents in a stratified ambient: shallow-water theory and numerical results. Journal of Fluid Mechanics, 535:287-323. [doi:10.1017/ S0022112005004854]

Ungarish, M., 2006. On gravity currents in a linearly stratified ambient: a generalization of Benjamin's steady-state propagation results. Journal of Fluid Mechanics, 548: 49-68. [doi:10.1017/S0022112005007421]

van Doormaal, J.P., Raithby, G.D., 1984. Enhancements of the SIMPLE method for predicting incompressible fluid flows. Numerical Heat Transfer, 7(2):147-163. [doi:10. 1080/01495728408961817] 
Wells, M., Nadarajah, P., 2009. The intrusion depth of density currents flowing into stratified water bodies. Journal of Physical Oceanography, 39(8):1935-1947. [doi:10.1175/ 2009JPO4022.1]

Yin, M., Shi, F., Xu, Z., 1996. Renormalization group based $\kappa-\varepsilon$ turbulence model for flows in a duct with strong curvature. International Journal of Engineering Science, 34(2):243-248. [doi:10.1016/0020-7225(95)00082-8]

\section{中文概要}

题 目: 温度分层对于污染物在水库中运行时间的影响

目 的: 水库存在的温度分层导致入流能够形成表层流、 间层流或者底层流。探讨温度分层的强弱对于污 染物以间层流方式运动时在水库中滞留时间的 影响。
创新点: 1. 通过伯努利能量方程, 推导出分层强度与间层 流运动时间的关系; 2 . 建立试验模型, 成功模拟 间层流运动。

方 法: 1. 通过理论推导, 得到温度分层的强度越大, 间 层流运动时间越短 (公式 13); 2. 在实验室中模 拟不同温度分层强度下的间层流运动, 验证理论 推导的关系式 (图 7); 3. 通过数值模拟技术, 模 拟温度分层存在时的间层流运动, 进一步验证温 度分层强度与间层流运动时间之间的关系 (图 12)。

结 论：1. 温度分层的存在会导致入流在分层水体中形成 不同形态的流动; 2. 温度分层强度的增加会导致 间层流在分层水体中运动时间变短; 3. 入流形成 间层流方式的不同对于分层强度与间层流运行 时间之间的关系没有影响。

关键词: 温度分层; 间层流; 分层强度; 浮力频率; 运动 时间 